Eduardo Trejo Lino

La cultura tributaria en México como instrumento de identidad nacional

Revista Xihmai XIII (26), 115-136, julio-diciembre 2018

\title{
Xihmai
}

Universidad La Salle Pachuca

xihmai@lasallep.edu.mx

Teléfono: 01(771) 7170213 ext. 1406

Fax: 01(771) 7170309

ISSN (versión impresa):1870-6703

México

Eduardo Trejo Lino

LA CULTURA TRIBUTARIA EN MÉXICO COMO INSTRUMENTO DE IDENTIDAD NACIONAL

THE TRIBUtARy TAX CULtURE IN MEXICO AS AN INSTRUMENT OF NATIONAL IDENTITY

Xihmai, año 2018/vol. XIII, número 26

Universidad La Salle Pachuca

pp. $115-136$ 
Eduardo Trejo Lino

La cultura tributaria en México como instrumento de identidad nacional Revista Xihmai XIII (26), 115-136, julio-diciembre 2018

Xihmai 116 
Eduardo Trejo Lino

La cultura tributaria en México como instrumento de identidad nacional Revista Xihmai XIII (26), 115-136, julio-diciembre 2018

\section{La CULTURA TRIBUTARIA EN MÉXICO COMO InSTRUMENTO DE IDENTIDAD NACIONAL}

THE TRIBUtARy TAX CULtURE IN MEXICO AS AN INSTRUMENT OF NATIONAL IDENTITY

Licenciado en Derecho por la Universidad Nacional Autónoma de México. Maestro en Derecho Fiscal por la Universidad del Valle de México. Candidato a Doctor en Política Criminal por la Universidad Popular Autónoma de Veracruz. Ha cursado diversos seminarios, cursos y diplomados en materia jurídica; se ha desempeñado como Abogado

Postulante desde 1990. Asesor Jurídico del Municipio de Villa de Tezontepec, Hidalgo, del Municipio de San Agustín Tlaxiaca, Hidalgo, y del Municipio de Molango de Escamilla, Hidalgo. Director Jurídico de Complejo Agropecuario Industrial de Tizayuca, S.A. de C.V., Grupo Real de Ganaderos S.A. de C.V., y Unión de Crédito Agroindustrial y Comercial de Tizayuca. Profesor de la Maestría en Derecho Civil, de la Licenciatura en Derecho y de la Maestría en Derecho Fiscal del Instituto Tecnológico Latinoamericano del Estado de Hidalgo.

\section{Recibido 14-10-17 Corregido 15-11-17 Aceptado 01-01-18}

\section{Resumen}

El artículo examina la actividad financiera del Estado en relación con el civismo fiscal que tienen los contribuyentes en nuestro país, teniendo como premisa los datos de la recaudación que se llevan a cabo sin que se ejerzan facultades de fiscalización, proporcionados por el Servicio de Administración Tributaria, analizando si en el cumplimiento de las obligaciones fiscales existe una cultura tributaria y si esta se puede fomentar sin que medie el temor a consecuencias legales ante su incumplimiento y su función como paradigma de reconstrucción del tejido social y de la identidad nacional.

\section{Abstract}

This article examines the financial activity of the State in relation with the civic responsibility that all contributors have in our Country, having in consideration that the data of the tax collection is carried out without the powers of taxation being exercised by the Tax Administration Service (Servicio de 
Eduardo Trejo Lino

La cultura tributaria en México como instrumento de identidad nacional

Revista Xihmai XIII (26), 115-136, julio-diciembre 2018

Administración Tributaria), analyzing if in the fulfillment of the fiscal obligations, a tributary tax culture exists among the citizens, and if it can be promoted without the fear of legal consequences to a breach or failure, and its function as a paradigm of reconstruction of the "social tissue" and the National Identity.

Palabras clave: Actividad Financiera, Contribuciones, Gasto Público, Obligación Fiscal, Ingresos Fiscales, Civismo Fiscal, Cultura Tributaria,Identidad Nacional.

Keywords: Financial activity, Civic responsibility, Tax Administration Service, fiscal obligations, tributary tax culture, National Identity.

\section{Introducción}

El 24 de noviembre de 2015, durante su participación en la 57 semana nacional de Radio y Televisión, el entonces Secretario de Hacienda y Crédito Público, Luis Videgaray Caso, al responder la pregunta que le fue formulada por un participante, “¿Por qué no bajan el impuesto de la renta a las empresas, que generará más inversión, más empleos y, por qué no también a las personas para que ellas aumenten su consumo?", manifestó: "El tema de los impuestos es un tema que a nadie nos gusta, porque a nadie nos gusta pagar impuestos, por eso se llaman impuestos, si no se llamarían a lo mejor voluntarios"'. Más allá del comentario anecdótico (a mi parecer bastante desafortunado, por ser pronunciado por la máxima autoridad fiscal en el país), sirve la referencia para cuestionarnos si verdaderamente los contribuyentes pagan los impuestos directos $^{2}$ sin que medie su voluntad, considerando, por supuesto, que la obligación fiscal surge por mandato constitucional ${ }^{3}$ y sin tomar en cuenta a aquellos que son sustituidos en el cumplimiento de la obligación por el régimen

\footnotetext{
1 Secretaría de Hacienda y Crédito Público. Versión estenográfica recuperada de https://www.gob.mx/shcp/archivo/prensa, de fecha 24 de noviembre de 2015.

2 "Los impuestos directos son aquellos cuya afectación tributaria incide de manera inmediata y rigurosa en el contribuyente por su capacidad contributiva o adquisitiva; es decir, se relacionan con la magnitud de los ingresos que se perciben o con el potencial de adquisición del contribuyente" (Ortega, 2012).

${ }^{3}$ El artículo 31, Fracción IV, de la Constitución Política de los Estados Unidos Mexicanos establece:

"Son obligaciones de los mexicanos: «Contribuir para los gastos públicos, así de la Federación, como de los Estados, de la Ciudad de México y del Municipio en que residan, de la manera proporcional y equitativa que dispongan las leyes»" (2017).
}

Xihmai 118 
en que tributan, como son entre otros, las personas físicas que perciben ingresos por salarios y en general por la prestación de un servicio personal subordinado, en cuyo caso pagan el Impuesto Sobre la Renta, a través del patrón o empleador mediante la retención correspondiente (Cámara de Diputados, 2016); surge un segundo interrogante: si en todo caso dicha voluntad refleja un grado de civismo fiscal, y lo más importante: ¿puede implementarse y asumirse un civismo fiscal en nuestro país que posibilite una convivencia armónica y que sirva como herramienta para acabar con el rezago económico, la desigualdad social y la inseguridad? El presente trabajo plantea una aproximación a la cultura tributaria como modelo de identidad nacional, recayendo su motivación en las autoridades fiscales.

\section{La actividad financiera del Estado}

\section{Derecho Financiero Público}

El contexto de la relación de supra a subordinación existente en la relación jurídica tributaria entre el Estado y el contribuyente y la actividad financiera que desarrolla para cumplir con sus objetivos y justificar dicha relación, se estudia en el derecho financiero público, también conocido como derecho de las finanzas públicas y derecho financiero; Mabarak Cerecedo (2004) señala que el derecho financiero público "es la rama del derecho integrada por un conjunto de normas que tienen por objeto regular las actividades económicas de los órganos públicos, tanto en lo que corresponde a la percepción de los ingresos, como en lo que respecta al ejercicio del gasto".

El objeto del derecho financiero público es el estudio y la aplicación de las finanzas públicas limitado al ámbito jurídico; sin embargo, en nuestro país, dicho estudio se ha centrado principalmente en el estudio del derecho fiscal, por lo que es escaso el conocimiento científico generado en las otras disciplinas que integran esta rama del derecho ${ }^{4}$, es el normar aquello que se relaciona jurídicamente con las finanzas del Estado, es decir con la capacitación y la administración de los recursos económicos estatales. Desde esa perspectiva, se puede decir que el derecho financiero es el conjunto de normas reguladoras de la actividad financiera del Estado que comprende la recaudación, gestión y empleo de los medios.

\section{Derecho Fiscal}

Carrasco Iriarte (2005) precisa que "El derecho fiscal es el conjunto de normas jurídicas que se encargan de regular las contribuciones en sus diversas

\footnotetext{
${ }^{4}$ El Derecho Presupuestario o presupuestal, el Derecho Patrimonial, el Derecho Crediticio o Derecho del crédito público, el Derecho Monetario y el Derecho Fiscal o Tributario son disciplinas generalmente aceptadas por la comunidad jurídica como partes del derecho financiero público.
} 
Eduardo Trejo Lino

La cultura tributaria en México como instrumento de identidad nacional Revista Xihmai XIII (26), 115-136, julio-diciembre 2018

manifestaciones. De ahí que el término se emplee para designar situaciones de distinta índole que se presentan con motivo de las contribuciones".

Por su parte, Venegas Álvarez indica que "El Derecho Fiscal o tributario es la rama del Derecho que se ocupa de las relaciones entre el fisco y las personas sujetas a imposiciones tributarias de cualquier especie, limitando el poder de tributar y protegiendo al ciudadano contra los abusos de ese poder".

Mabarak Cerecedo señala que "El derecho fiscal se conceptúa como la rama del derecho financiero que tiene por objeto regular las relaciones jurídicas que se dan entre el Estado, en su carácter de autoridad fiscal, y los gobernados, ya sea que estos asuman el papel de contribuyentes, responsables solidarios o terceros, y cuyo objetivo fundamental es el de la recaudación de los tributos". La doctrina moderna del derecho financiero conceptualiza la voz contribución como la carga unilateral determinada por la ley a cargo de los habitantes de un Estado, destinada a satisfacer el gasto público (Yanome, 2009).

El tributo, contribución o ingreso tributario es el vínculo jurídico en virtud del cual el Estado, al actuar como sujeto activo, exige a un particular, denominado sujeto pasivo, el cumplimiento de una prestación pecuniaria, excepcionalmente en especie (Margáin,2009).

\section{La hacienda pública y las contribuciones}

La hacienda pública se encuentra regulada en los artículos 74, fracción IV, 75, 126, 127 y 134 de la Constitución Política de los Estados Unidos Mexicanos, relativos a las materias de programación, presupuestación, aprobación, ejercicio, control y evaluación de los ingresos y egresos públicos federales, por lo que se advierte que tiene diversas connotaciones: doctrinaria, patrimonial y de competencia, es decir, se trata de una disciplina que tiene como objeto el estudio de la actividad financiera del Estado, patrimonial como el conjunto de bienes y cargas que aquél posee y como las facultades que corresponden a las autoridades en quienes recae la materialización de los fines de la hacienda pública.

\section{Los ingresos del Estado y el ejercicio del gasto público}

El estado sin ingresos no podría existir, absolutamente todas las funciones que realiza a través de los poderes constituidos y demás organismos de las competencias federal, estatal y municipal, requieren ingresos y su correspondiente ejercicio presupuestal; no existe una actividad estatal que se realice sin la intervención de la hacienda pública, cuya finalidad es lograr lo que los teóricos han denominado de manera específica el bien común y en general la justicia social, la seguridad pública, la libertad, la seguridad jurídica y la convivencia pacífica y en armonía entre todos los integrantes del Estado;

Xihmai 120 
Eduardo Trejo Lino

La cultura tributaria en México como instrumento de identidad nacional

Revista Xihmai XIII (26), 115-136, julio-diciembre 2018

comentario aparte merece el hecho que es de sobra conocido que las necesidades de la población a quienes van dirigidas las actividades del Estado siempre serán mayores a los recursos con los que éste cuenta, así como que existe la percepción generalizada que buena parte de esos recursos son empleados de forma deficiente y en otros para beneficio particular de aquellos a quienes legalmente se les encarga su administración y ejercicio, según lo ha documentado Transparencia Internacional y divulgado el Instituto Mexicano de Competitividad en su página $w_{e b}^{5}$.

De igual forma, la actividad del Estado en el ejercicio del gasto público se vincula con la rectoría económica que tiene para garantizar el crecimiento económico del país, de conformidad con los artículo 25 y 26 de nuestro máximo ordenamiento jurídico, lo que ha sido ampliamente debatido por el pleno de la Suprema Corte de Justicia de la Nación para delimitar dichas atribuciones (Suprema Corte de Justicia de la Nación, 2009, p. 1543).

Lo anterior nos permite afirmar que, sin un equilibrio entre los ingresos del Estado y el ejercicio del gasto público, o dicho de otra manera, entre la responsabilidad del contribuyente para cumplir con sus obligaciones fiscales $\mathrm{y}$, por otra, la responsabilidad de la autoridad en el ejercicio legal y moral del gasto público, no será posible alcanzar los fines del Estado, posición que no parte desde una perspectiva filosófica (lo que también es necesario, por supuesto), sino de una postura sencilla de sentido común.

En consecuencia, la actividad financiera del Estado consiste en una serie de actos tendientes a obtener ingresos para efectuar el gasto público ${ }^{6}$ y la forma de administrarlos.

\footnotetext{
5 “A pesar de los esfuerzos por establecer un nuevo sistema anticorrupción, México volvió a caer en el Índice de Percepción de la Corrupción que realiza todos los años la organización Transparencia Internacional (TI). En esta edición, nuestro país ocupa el lugar 135 de 180 naciones evaluadas, mientras que en el mismo estudio, en 2016, se ubicó en el sitio 123 de 176. Este año el reporte evalúa a 180 países (cuatro más que la edición anterior) y mide aspectos como el gobierno abierto, la rendición de cuentas, la libertad de expresión, la transparencia, los niveles de integridad en el servicio público y el acceso igualitario a la justicia. La calificación tiene una escala de 0 a 100 , donde 0 es el peor resultado y 100 el mejor" (IMCO, 2017).

6 Ley Federal del Presupuesto y Responsabilidad Hacendaria, 2015. Obtenido de http://www.diputados.gob.mx/LeyesBiblio/pdf/LFPRH_301215.pdf

Artículo 4.- El gasto público federal comprende las erogaciones por concepto de gasto corriente, incluyendo los pagos de pasivo de la deuda pública; inversión física; inversión financiera; así como responsabilidad patrimonial; que realizan los siguientes ejecutores de gasto:

I. El Poder Legislativo;

II. El Poder Judicial;

III. Los entes autónomos;

IV. Los tribunales administrativos;
} 
Eduardo Trejo Lino

La cultura tributaria en México como instrumento de identidad nacional

Revista Xihmai XIII (26), 115-136, julio-diciembre 2018

\section{Recursos Financieros}

Respecto a los recursos económicos o financieros, Alfonso Cortina Gutiérrez, cuando alude a las finanzas públicas, dice que éstas se refieren "a todos los medios económicos del Estado para satisfacer sus erogaciones", los cuales clasifica en cuatro categorías: recursos tributarios, precios públicos, empréstitos, tanto de fuentes externas como internas, emisión de moneda (Cortina, 1977).

En términos generales, los ingresos del Estado son establecidos en un documento legal denominado "presupuesto de ingresos", conocido en México como Ley de Ingresos ${ }^{7}$, en donde se incorporan todos aquellos conceptos por

V. La Procuraduría General de la República;

VI. La Presidencia de la República;

VII. Las dependencias, y

VIII. Las entidades.

Los ejecutores de gasto antes mencionados están obligados a rendir cuentas por la administración de los recursos públicos en los términos de la presente Ley y demás disposiciones aplicables.

Las disposiciones presupuestarias y administrativas fortalecerán la operación y la toma de decisiones de los ejecutores, procurando que exista un adecuado equilibrio entre el control, el costo de la fiscalización, el costo de la implantación y la obtención de resultados en los programas y proyectos.

La Presidencia de la República se sujetará a las mismas disposiciones que rigen a las dependencias. Asimismo, la Procuraduría General de la República y los tribunales administrativos se sujetarán a las disposiciones aplicables a las dependencias, así como a lo dispuesto en sus leyes específicas dentro del margen de autonomía previsto en el artículo 5 de esta Ley.

Los ejecutores de gasto contarán con una unidad de administración, encargada de planear, programar, presupuestar, en su caso establecer medidas para la administración interna, controlar y evaluar sus actividades respecto al gasto público.

Artículo 5.- La autonomía presupuestaria otorgada a los ejecutores de gasto a través de la Constitución Política de los Estados Unidos Mexicanos o, en su caso, de disposición expresa en las leyes de su creación, comprende:

I. En el caso de los Poderes Legislativo y Judicial y los entes autónomos, conforme a las respectivas disposiciones constitucionales, las siguientes atribuciones:

a) Aprobar sus proyectos de presupuesto y enviarlos a la Secretaría para su integración al proyecto de Presupuesto de Egresos, observando los criterios generales de política económica;

b) Ejercer sus presupuestos observando lo dispuesto en esta Ley, sin sujetarse a las disposiciones generales emitidas por la Secretaría y la Función Pública. Dicho ejercicio deberá realizarse con base en los principios de eficiencia, eficacia y transparencia y estarán sujetos a la normatividad, la evaluación y el control de los órganos correspondientes;

c) Autorizar las adecuaciones a sus presupuestos sin requerir la autorización de la Secretaría, observando las disposiciones de esta Ley;

${ }^{7}$ La Ley de Ingresos de la Federación tiene como función primordial dar vigencia en la aplicación de las diversas leyes que en materia contributiva existen, en esta se justifica el principio constitucional de que toda contribución es para el gasto público, junto con el presupuesto de egresos público. La vigencia constitucional de la Ley de Ingresos de la Federación es de un año. Xihmai 122 
Eduardo Trejo Lino

La cultura tributaria en México como instrumento de identidad nacional

Revista Xihmai XIII (26), 115-136, julio-diciembre 2018

los cuales el Estado tendrá derecho a percibir recursos durante un ejercicio fiscal ${ }^{8}$; por su parte el Código Fiscal de la Federación establece los principios generales aplicables a las leyes especiales y las definiciones esenciales de la materia fiscal, así como particulariza los supuestos jurídicos mediante los cuales el Estado ejerce su función recaudatoria, determinando los derechos y obligaciones de los sujetos de la norma jurídica tributaria (Estado y particular). Por su parte, las contribuciones en general se especifican en leyes especiales que establecen los alcances y límites y las reglas de su funcionamiento en general.

\section{Clasificación de los Ingresos del Estado}

Los ingresos del Estado se clasifican en patrimoniales, financieros y fiscales, los cuales se definen de la siguiente forma:

El artículo 1 de la Ley de Ingresos de la Federación para el ejercicio fiscal de 2018 establece que se percibirá un ingreso total de \$5'279,667.0 (millones de pesos).

${ }^{8}$ La Constitución Política de los Estados Unidos Mexicanos establece:

Artículo 73. El Congreso tiene facultad:

....XXVIII. Para expedir leyes en materia de contabilidad gubernamental que regirán la contabilidad pública y la presentación homogénea de información financiera, de ingresos y egresos, así como patrimonial, para la Federación, las entidades federativas, los Municipios y las demarcaciones territoriales de la Ciudad de México, a fin de garantizar su armonización a nivel nacional;

Artículo 74. Son facultades exclusivas de la Cámara de Diputados:

.... IV. Aprobar anualmente el Presupuesto de Egresos de la Federación, previo examen, discusión y, en su caso, modificación del Proyecto enviado por el Ejecutivo Federal, una vez aprobadas las contribuciones que, a su juicio, deben decretarse para cubrirlo. Asimismo, podrá autorizar en dicho Presupuesto las erogaciones plurianuales para aquellos proyectos de inversión en infraestructura que se determinen conforme a lo dispuesto en la ley reglamentaria; las erogaciones correspondientes deberán incluirse en los subsecuentes Presupuestos de Egresos.

El Ejecutivo Federal hará llegar a la Cámara la Iniciativa de Ley de Ingresos y el Proyecto de Presupuesto de Egresos de la Federación a más tardar el día 8 del mes de septiembre, debiendo comparecer el secretario de despacho correspondiente a dar cuenta de los mismos. La Cámara de Diputados deberá aprobar el Presupuesto de Egresos de la Federación a más tardar el día 15 del mes de noviembre.

Cuando inicie su encargo en la fecha prevista por el artículo 83, el Ejecutivo Federal hará llegar a la Cámara la iniciativa de Ley de Ingresos y el proyecto de Presupuesto de Egresos de la Federación a más tardar el día 15 del mes de noviembre. No podrá haber otras partidas secretas, fuera de las que se consideren necesarias, con ese carácter, en el mismo presupuesto; las que emplearán los secretarios por acuerdo escrito del Presidente de la República. Sólo se podrá ampliar el plazo de presentación de la iniciativa de Ley de Ingresos y del Proyecto de Presupuesto de Egresos, cuando medie solicitud del Ejecutivo suficientemente justificada a juicio de la Cámara o de la Comisión Permanente, debiendo comparecer en todo caso el Secretario del Despacho correspondiente a informar de las razones que lo motiven (Cámara de diputados. (15 de septiembre de 2017). Obtenido de http://www.diputados.gob.mx/LeyesBiblio/pdf/1_150917.pdf).

Xihmai 123 
Eduardo Trejo Lino

La cultura tributaria en México como instrumento de identidad nacional

Revista Xihmai XIII (26), 115-136, julio-diciembre 2018

a) Ingresos patrimoniales. "Son aquellos que obtiene el Estado por la explotación de su patrimonio, es decir, de la explotación de los bienes de su dominio privado, verbigracia aquellos que percibe Petróleos Mexicanos o la CFE” (Sánchez, 2013).

En esta categoría se encuentran los productos, los que se pueden definir como los ingresos que perciben organismos y empresas del Estado como contraprestación por las relaciones jurídicas que establece en un plano de coordinación, es decir, en ejercicio de actos de derecho privado. El artículo 3, último párrafo, del Código Fiscal de la Federación, proporciona una definición legal de los productos ${ }^{9}$.

La Ley de Ingresos de la Federación para el ejercicio fiscal 2018 prevé obtener por ingresos por ventas de bienes y servicios la cantidad de \$884,070.9 (en millones de pesos) y por productos $\$ 6,427.1$ (en millones de pesos).

b) Ingresos financieros. "Todos aquellos que provienen de las diversas fuentes de financiamiento a las que el Estado se ve precisado a recurrir en adición a las prestaciones fiscales recibidas de los contribuyentes, para integrar el Presupuesto Nacional (Arrioja, 2012)".

La ley de Ingresos de la Federación para el ejercicio fiscal 2018 prevé obtener por ingresos derivados de financiamientos la suma de $\$ 501,375.5$ (en millones de pesos).

c) Ingresos fiscales. Son aportaciones económicas de las personas que en su calidad de sujetos pasivos de la relación jurídica tributaria, se encuentran en las situaciones de hecho o derecho previstas en las leyes como causas generadoras de la obligación constitucional de contribuir ${ }^{10}$ a los gastos públicos. De conformidad con el artículo 2 del Código Fiscal de la Federación, se desprenden cinco clases de contribuciones: impuestos, aportaciones de seguridad social, contribuciones de mejoras, derechos y aprovechamientos, sin que estos sean propiamente contribuciones, se les agrupa como tales por ser complementarios, en su calidad accesoria.

La Ley de Ingresos de la Federación 2018 estima un total de \$3’584,918.4 (en millones de pesos), sin contar las aportaciones de seguridad social, las cuales

\footnotetext{
${ }^{9}$ Son productos las contraprestaciones por los servicios que preste el Estado en sus funciones de derecho privado, así como por el uso, aprovechamiento o enajenación de bienes del dominio privado.

${ }^{10}$ Contribuir es proporcionarle al Estado los recursos económicos necesarios para que éste, a su vez, provea los servicios y bienestar que reclamamos día a día (Ortega, 2012).
}

Xihmai 124 
suman un monto de $\$ 309,302.2$ (en millones de pesos), lo que hace un total, en millones de pesos, de \$3'894220.6, lo que representa aproximadamente el $73 \%$ de los ingresos totales que percibirá el Estado para el ejercicio fiscal 2018, que asciende a la suma de $\$ 5,279,667.0$ (en millones de pesos).

\section{Situación actual de los contribuyentes en relación con el cumplimiento de sus obligaciones fiscales}

El sujeto pasivo de la relación jurídica tributaria, denominado contribuyente, es la persona en quien de manera directa recae la obligación de pagar la contribución, una vez ocurra el hecho imponible ${ }^{11}$, lo que de suyo implica el principio de generalidad tributaria; al respecto, la Primera Sala de la Suprema Corte de Justicia de la Nación ha sustentado que "el principio de generalidad tributaria se configura como la condición necesaria para lograr la igualdad en la imposición y como un mandato dirigido al legislador tributario para que al tipificar los hechos imponibles de los distintos tributos agote, en lo posible, todas las manifestaciones de capacidad económica, buscando la riqueza donde ésta se encuentra" (Suprema Corte de Justicia de la Nación, 2009, p. 552).

En nuestro país, el número de contribuyentes formalmente inscritos en el Registro Federal de Contribuyentes ${ }^{12}$ aumentó a más del doble en un plazo aproximado de ocho años, como se demuestra con las siguientes gráficas publicadas en el sitio electrónico del Servicio de Administración Tributaria, donde se destaca que el padrón alcanzó 61 millones de contribuyentes, de los cuales $56.5 \%$ son asalariados, $40.4 \%$ son personas físicas y $3.1 \%$ son personas morales o empresas; los grandes contribuyentes representan menos de $1 \%$ de los registros.

\section{Padrón | Por situación ante el RFC Número de contribuyentes (acumulado)}

\begin{tabular}{|c|c|c|c|c|}
\hline Año & Mes & Activos & Suspendidos & Cancelados \\
\hline 2010 & Enero & $28,369,038$ & $5,525,611$ & 271,774 \\
\hline 2017 & Diciembre & $64,672,335$ & $7,206,555$ & 914,016 \\
\hline
\end{tabular}

\footnotetext{
${ }^{11}$ Hipótesis legal que establece el sujeto y el objeto de la contribución.

12 "El Registro Federal de Contribuyentes (RFC) es una clave alfanumérica que se compone de 13 caracteres. Los dos primeros, generalmente corresponden al apellido paterno, el tercero a la inicial del apellido materno y el cuarto al primer nombre. Le sigue el año de nacimiento, mes y día; los tres últimos dígitos son la homoclave que es asignada por el Servicio de Administración Tributaria (SAT). Éste sirve para evitar claves duplicadas y homónimos. El documento que te expide la autoridad es el acuse de inscripción en el RFC con Cédula de Identificación Fiscal".
} 
Eduardo Trejo Lino

La cultura tributaria en México como instrumento de identidad nacional

Revista Xihmai XIII (26), 115-136, julio-diciembre 2018

\begin{tabular}{|c|c|c|c|c|c|c|c|}
\hline Año & Mes & $\begin{array}{c}\text { Personas } \\
\text { Físicas }\end{array}$ & $\begin{array}{c}\text { Grandes } \\
\text { Contribuyentes } \\
\text { (PF) }\end{array}$ & $\begin{array}{l}\text { Asalariados } \\
\text { (PF) }\end{array}$ & $\begin{array}{l}\text { Personas } \\
\text { Morales }\end{array}$ & $\begin{array}{c}\text { Grandes } \\
\text { Contribuyentes } \\
\text { (PM) }\end{array}$ & Total \\
\hline 2010 & Enero & $10,587,312$ & 4 & $16,562,605$ & $1,205,310$ & 13,807 & $28,369,038$ \\
\hline 2017 & Diciembre & $24,780,762$ & 23,205 & $37,926,366$ & $1,932,287$ & 9,715 & $64,672,335$ \\
\hline
\end{tabular}

En el Informe Tributario y de Gestión ${ }^{13}$, Tercer trimestre de 2017, el Servicio de Administración Tributaria comunicó:

Al tercer trimestre de 2017, los ingresos tributarios no petroleros se ubicaron en dos billones 182 mil 670.7 millones de pesos, esto es 101 mil 688.6 millones de pesos más que lo presupuestado en la Ley de Ingresos de la Federación (LIF). Con respecto al tercer trimestre de 2016, los ingresos aumentaron $1.0 \%$ en términos reales. - El crecimiento del padrón de contribuyentes continúa mostrando un gran dinamismo. A septiembre de 2017, dicho padrón está conformado por poco más de 63 millones de contribuyentes, lo que significa un aumento de 8.3 millones de contribuyentes $(15.2 \%)$ respecto al mismo mes del año anterior. • A septiembre de 2017, el número de contribuyentes inscritos en el Régimen de Incorporación Fiscal fue de 4 millones 912 mil 168 contribuyentes. Desde su comienzo en 2014, los contribuyentes de este régimen han emitido 281.1 millones de facturas. • En el periodo enero septiembre de 2017, se emitieron 202 facturas por segundo, esto es diez facturas más que al mismo periodo del año anterior (SAT, 2017).

En el Informe Tributario y de Gestión del primer trimestre de 2018, rendido por el SAT, el padrón está conformado por 6.7 millones de contribuyentes, lo que significa un aumento de 6.7 millones $(11.2 \%)$ respecto al mismo mes del año anterior.

De igual forma, en el informe que se comenta, se destaca que durante el primer trimestre de 2018, se recaudaron 15 mil 134.7 millones de pesos derivados de los actos de control de obligaciones, lo que implica un aumento de $54 \%$ en términos reales en comparación con el mismo periodo de 2017 (9 mil 461.4 millones de pesos).

En el mismo periodo se recaudaron 33 mil 526.8 millones de pesos por actos de fiscalización, monto menor en 2 mil 674.4 millones de pesos al obtenido en el periodo similar de 2017 (12.1\% menor en términos reales).

Como se advierte de los informes presentados por la autoridad fiscal, la suma recaudada por el control de obligaciones y fiscalización no rebasa los $\$ 50,000$

\footnotetext{
${ }^{13}$ Documento que trimestralmente difunde los principales resultados de la recaudación de los ingresos del gobierno federal, así como las actividades que la Institución tiene encomendadas (SAT).

Xihmai 126
} 
millones de pesos millones de pesos, cantidad que resulta sumamente baja en comparación con el total estimado a recaudar por contribuciones (\$3’894220.6 millones de pesos), lo que representa el $1.28 \%$ del total.

Los datos anteriores nos permiten concluir que, descontando a los 38.8 millones de personas que tributan en el régimen de asalariados y asimilables a sueldos y salarios (SAT, 2018) que se consideran contribuyentes cautivos por cumplir con sus obligaciones fiscales mediante las retenciones que les hacen sus patrones o empleadores, el resto de los contribuyentes cumple de manera voluntaria con su obligación de contribuir al gasto público (sin que sea óbice que las contribuciones son auto aplicativas ${ }^{14}$ ), es decir, el contribuyente cumple de forma voluntaria, pues no podemos obviar que, si bien es cierto que el incumplimiento de las obligaciones fiscales tiene como consecuencia no solo sanciones pecuniarias sino penales, también lo es, como se ha demostrado en el ejercicio de las facultades de fiscalización, que lo anterior es mínimo comparado con la unilateralidad del contribuyente al cumplir con sus obligaciones fiscales.

\section{La Cultura Tributaria}

La cultura tributaria es una conducta manifestada en el cumplimiento permanente de los deberes tributarios con base en la razón, la confianza, la leal aplicación de los recursos y la afirmación de los valores de ética personal, respeto a la ley, responsabilidad ciudadana y solidaridad social de todos (SAT); en nuestro país, existe un sistema fiscal sumamente complejo en su entendimiento y su aplicación; las leyes fiscales resultan confusas y extensas y tienen un sentido totalmente recaudatorio, por lo que los actos y las facultades imperativas de la autoridad, al ejercerse en múltiples ocasiones, contrarían la definición brindada de cultura tributaria, ya que la autoridad tiene soberanía sobre el gobernado y puede ejercerla para obligar el cumplimiento de sus obligaciones, perdiendo así un elemento que es la confianza.

\footnotetext{
14 "Artículo 6 del Código Fiscal de la Federación.-

Las contribuciones se causan conforme se realizan las situaciones jurídicas o de hecho, previstas en las leyes fiscales vigentes durante el lapso en que ocurran.

Dichas contribuciones se determinarán conforme a las disposiciones vigentes en el momento de su causación, pero les serán aplicables las normas sobre procedimiento que se expidan con posterioridad.
}

Corresponde a los contribuyentes la determinación de las contribuciones a su cargo, salvo disposición expresa en contrario.

Si las autoridades fiscales deben hacer la determinación, los contribuyentes les proporcionarán la información necesaria dentro de los 15 días siguientes a la fecha de su causación" (Cámara de Diputados, 2018).

Xihmai 127 
Eduardo Trejo Lino

La cultura tributaria en México como instrumento de identidad nacional

Revista Xihmai XIII (26), 115-136, julio-diciembre 2018

A continuación se analizarán los elementos de la definición proporcionada por la autoridad fiscal.

\section{Razón}

El Diccionario de la lengua española define la razón como la facultad para pensar, reflexionar e inferir, el argumento que se expone en respaldo hacia una determinada cosa, el motivo o causa, y el cociente de dos cifras; podemos entender que es la capacidad que se tiene para prever o entender determinados temas; en materia tributaria es aplicable respecto a los alcances que tienen las personas de inferir el uso que se dará a las aportaciones realizadas o las consecuencias sociales que acarrea su incumplimiento, así como los beneficios o perjuicios que se obtendrán, toda vez que los ciudadanos no pueden participar en la decisión del uso de los fondos públicos de conformidad con el numeral 3, de la fracción VIII, del artículo 35 de la Constitución Política de los Estados Unidos Mexicanos ${ }^{15}$.

Con la finalidad de poder determinar cuál es el uso que se da a los ingresos acumulados por la Secretaria de Hacienda y Crédito Público, existen distintos medios para que el gobernado pueda enterarse; en primer lugar, en el Diario Oficial de la Federación, el Presupuesto Federal de Egresos de la Federación se publica anualmente y establece los gastos que las autoridades realizarán a lo largo del año, desde el inicio de la vigencia. Otro medio es a través de los portales electrónicos o teniendo contacto directo con las autoridades. México es parte de la Alianza para el Gobierno Abierto, una iniciativa internacional que busca promover la transparencia y la rendición de cuentas de los gobiernos, así como impulsar la participación ciudadana. Con ello, la Secretaría de Hacienda y Crédito Público forma parte activa del grupo que impulsa la transparencia social.

En ese sentido si bien no se hace un participación directa con la sociedad lo cierto es que en el "deber ser", los ciudadanos mexicanos tienen el derecho de conocer de primera mano y hacer conciencia del uso que se dará a las

\footnotetext{
15 "Artículo 35. Son derechos del ciudadano:

VIII. Votar en las consultas populares sobre temas de trascendencia nacional, las que se sujetarán a lo siguiente:

3o. No podrán ser objeto de consulta popular la restricción de los derechos humanos reconocidos por esta Constitución; los principios consagrados en el artículo 40 de la misma; la materia electoral; los ingresos y gastos del Estado; la seguridad nacional y la organización, funcionamiento y disciplina de la Fuerza Armada permanente. La Suprema Corte de Justicia de la Nación resolverá, previo a la convocatoria que realice el Congreso de la Unión, sobre la constitucionalidad de la materia de la consulta" (Cámara de diputados, 2017).
}

Xihmai 128 
Eduardo Trejo Lino

La cultura tributaria en México como instrumento de identidad nacional Revista Xihmai XIII (26), 115-136, julio-diciembre 2018

contribuciones aportadas al gasto público, el cual debe de ser en beneficio de la sociedad en general.

\section{Confianza}

Entendemos como facultades imperativas las previstas en distintas disposiciones fiscales, aquellas en las que la autoridad tiene la potestad de obligar. Rafael de Pina Vara define la inoperatividad como la "característica que surge del hecho de que la norma obliga o manda su cumplimento, independientemente de si se desea cumplir con ella, o no" (De Pina Vara, 2012), con lo que podemos afirmar que aquella persona que realice algún acto o hecho, como la obtención de ingresos o la realización de contratos traslativos de dominio, previstos en una norma jurídica, inminentemente está obligada a su cumplimiento, es decir al pago de los impuestos correspondientes establecidos en una disposición legal y no a su arbitrio o a la confianza que la autoridad le deposite.

Según la página electrónica de El Economista, los países que tienen más altos porcentajes tributarios son: en primer lugar Bélgica, Alemania en segundo y Dinamarca en tercero con un porcentaje sobre salario bruto de $40.7 \%, 39.7 \%$ y $36.2 \%$, respectivamente (Riquelme, 2017); de igual manera en promedio, el $15 \%$ de la población total de estos países vive en la informalidad, teniendo un porcentaje de $85 \%$ de sus gobernados tributando para que el Estado pueda brindar servicios al 100\% de la misma. Según datos de INEGI (2017), el 51\% de los mexicanos no paga impuestos, ya que obtienen ingresos de distintas fuentes informales, es decir, el Estado tiene la obligación de cubrir necesidades establecidas en la Constitución Política de toda su población con recursos procedentes de menos de la mitad de la misma; consecuentemente, se crea una sobrecarga de obligaciones para el porcentaje de personas que tributan por las actividades que realizan.

En ese sentido, en países como Bélgica, Francia o Alemania, la autoridad tiene facultades imperativas para con sus gobernados en materia de contribuciones al igual que en México, como se puede apreciar en sus disposiciones; en el caso de Alemania, en su ley tributaria llamada "Handelsgesetzbuch-HGB" (Deutsche Gesetzestexte), se prevén las facultades de comprobación de las autoridades y los medios de apremio en caso de incumplimiento, pero aun así, a pesar de que en Alemania y México el sistema se basa más en la imperatividad que en la confianza, la cantidad de personas que tributan es mucho mayor en Alemania que en México, aproximadamente el 34\% de diferencia. 
Eduardo Trejo Lino

La cultura tributaria en México como instrumento de identidad nacional

Revista Xihmai XIII (26), 115-136, julio-diciembre 2018

\section{Leal aplicación de los recursos}

El Diccionario de la lengua española define el término recurso como el conjunto de elementos disponibles para resolver una necesidad o llevar a cabo una empresa, es decir que es el medio a través del cual el Estado realiza actos o actividades con el fin de satisfacer las necesidades de la sociedad con la que se encuentra obligado; en ese sentido, los recursos que son obtenidos mediante su carácter de ente perceptor de tributos deben tener un fin específico debidamente justificado y se debe acreditar que se destinó al mencionado.

La aplicación de los recursos, según el elemento de la definición de la conciencia tributaria, debe ser leal, entendiendo por leal que debe ir de acuerdo con los fines de la sociedad, como lo es su crecimiento económico, cultural, social, entre otros; por lo que podemos inferir que toda práctica que no va de acuerdo con el cumplimiento de estos objetivos, que en vez de beneficiar todas las necesidades de la sociedad, solo beneficiando a un grupo en específico, debe ser calificada como desleal y por ende vulneradora de la cultura tributaria. Este elemento va de la mano con el anterior, toda vez que siempre que la sociedad confíe en la autoridad que está imponiendo el impuesto, cumplirá con sus correspondientes obligaciones, es decir, a pesar de que la autoridad no deposita confianza en el gobernado al tener facultades imperativas, si este acredita el leal uso de los recursos destinados a un fin en específico, aquellos serán incentivados a contribuir voluntariamente y así ambas partes se verían beneficiadas, cumpliendo la autoridad con el fin para el cual fue creada.

En ese sentido, como se mencionó anteriormente, si bien es cierto que hay derechos constitucionales de los gobernados que el Estado, en teoría, está obligado a cubrir, lo cierto es que los recursos obtenidos en países como México no son suficientes para satisfacer dicha demanda, como subraya la OCDE. Los bajos ingresos de América Latina impiden a los Estados hacer la inversión necesaria en educación, infraestructura y desarrollo productivo, los cuales, junto con la salud y la protección social, son instrumentos clave para incrementar la productividad, la competitividad y la inclusión social (OCDECEPAL-CIAT, p. 46).

En México, existen casos contados de autoridades investidas de poder que enfrentan procesos penales por desviación de recursos, es decir que los recursos obtenidos no fueron destinados al bien común, sino al enriquecimiento ilícito de determinados funcionarios, obstruyendo por completo este elemento de la cultura tributaria (Flores, 2018).

\section{Afirmación de los valores de ética personal}

La ética se define como (del latín ethǐcus, y este del griego èthikós; del latín tardío ethǐca, y este del griego ēthiké [Fiesser) o filosofía

Xihmai 130 
moral; es la rama de la filosofía que estudia lo correcto o equivocado del comportamiento humano, la moral, la virtud, el deber, la felicidad y el buen vivir, siendo un ente subjetivo, ya que lo que es ético para una persona, puede ser no ético para otra; por ende, en el derecho tributario lo ético no es aquello que está bien o mal, más bien es aquello que va de acuerdo con los fines sociales, es decir aquello que ayuda al cumplimiento de los objetivos planteados por la sociedad, siendo estos por ejemplo el bienestar.

En ese sentido, los valores que rigen a cada una de las personas que son obligados de tributar no deben de ser regidos de manera personal, sino que deben prevalecer cuestionamientos grupales de los que se infieran las consecuencias de hacer caso omiso al pago de contribuciones.

De conformidad con el artículo 31, fracción IV, de la Constitución Política de los Estados Unidos Mexicanos, los ingresos obtenidos por el fisco federal son destinados a cubrir el gasto público; por ende la falta de pago de las mismas no afecta de manera directa al omiso, sino que se ve afectada la sociedad en general.

Algunos valores presentes, tanto en los contribuyentes como en los entes encargados de Administrar los recursos provenientes de los tributos, deben ser los siguientes:

a) Responsabilidad: Viene del latín responsum (respuesta) y dare (dar), que significa responder de lo hecho, de nuestros propios actos y consecuencias, bien ante uno mismo, por la conciencia, o ante alguien. Responsable es alguien capaz de justificar sus acciones, de explicar, de dar razón de lo que hizo y por qué lo hizo.

b) Cooperación: viene del latín cooperãri, que significa "Obrar juntamente con otro u otros para un mismo fin". La cooperación consiste en el trabajo en común llevado a cabo por un grupo de personas o entidades mayores hacia un objetivo compartido. Unir esfuerzos y establecer líneas de acción conjunta entre los contribuyentes y los organismos públicos, sobre el aspecto tributario.

c) Compromiso: Un compromiso o una cláusula compromisoria es, en Derecho, una estipulación contenida en un contrato por la que las partes acuerdan cumplir con lo establecido. Es un arreglo de intereses en conflicto que da a cada adversario la satisfacción de pensar que ha conseguido lo que no debió conseguir, y que no le han despojado de nada salvo lo que en justicia le correspondía. 
Eduardo Trejo Lino

La cultura tributaria en México como instrumento de identidad nacional

Revista Xihmai XIII (26), 115-136, julio-diciembre 2018

d) Solidaridad: es un término muy recurrente que habitualmente se emplea para denominar la simple acción dadivosa o bienintencionada. En sociología, solidaridad se refiere al sentimiento de unidad basado en metas o intereses comunes.

\section{Conclusiones}

1. Si la autoridad fiscal proporciona objetivos concretos que sirvan de inspiración motivacional a los contribuyentes, la recaudación aumentará en nuestro país sin el elemento de la inconformidad y el encono social contra el Estado.

2. La motivación para fomentar la cultura tributaria tiene que apartarse de la publicidad oficial en la que se presumen los resultados, propaganda que en ocasiones tiene un costo más alto que la obra política a difundir (Vargas, 2018).

3. La cultura tributaria no es un aspecto que únicamente afecta a los gobernados; se trata de un sinfín de prácticas realizadas tanto por particulares como por autoridades con objetivos idénticos, ya que, como se hizo mención, la autoridad, al igual, que el gobernado debe buscar el crecimiento social en sus distintos aspectos.

4. Cumplir con los elementos de la cultura tributaria es esencial para poder lograr la misma, lo que significa que el contribuyente debe tener conciencia de los elementos que envuelven a una contribución así como los alcances de la misma para así poder inferir las consecuencias que atrae su cumplimiento o incumplimiento y así generar una estrecha relación basada en la confianza.

5. La confianza entre las partes no limita a la autoridad de ejercer sus facultades de comprobación o ejecución en contra del incumplimiento de las obligaciones fiscales.

6. En la medida en que se consolide la confianza en la apreciación de la ciudadanía, respecto al uso transparente, equitativo y correcto de los ingresos en el ejercicio del gasto público por parte de la autoridad hacendaria, se aumentará la recaudación, pues es referente nacional la capacidad de solidaridad que tiene el pueblo mexicano, como ha quedado demostrado en la ayuda proporcionada a las personas que han sufrido desastres naturales; en este sentido, al establecerse un vínculo de confianza entre el contribuyente y el fisco, se fortalecerá la identidad nacional, lo que será una de las bases para la reconstrucción del tejido social y en contra de la desigualdad, la inseguridad, la corrupción y el atraso económico.

Xihmai 132 
Eduardo Trejo Lino

La cultura tributaria en México como instrumento de identidad nacional Revista Xihmai XIII (26), 115-136, julio-diciembre 2018

\section{FUENTES DE CONSUlta}

ÁlvareZ AlCALÁ, A. (2015). Lecciones de Derecho Fiscal. México: Oxford.

ARRIOJA VIZCAÍNO, A. (2012). Derecho fiscal. México: Themis.

CÁMARA DE DIPUTADOS (2017). Recuperado de http://www.diputados.gob.mx/LeyesBiblio/pdf/1_150917.pdf

CÁMARA DE DIPUTADOS (2018). Recuperado de http://www.diputados.gob.mx/LeyesBiblio/pdf/8_250618.pdf

CÁMARA DE DIPUTADOS (2016). Recuperado de http://www.diputados.gob.mx/LeyesBiblio/pdf/LISR_301116.pdf

CARRASCO IRIARTE, H. (2005). Derecho fiscal I. México: IURE.

CORTINA GUTIÉRREZ, A. (1977). Curso de política de finanzas públicas de México. México: Porrúa.

DE PINA VARA, R. (2012). Diccionario de Derecho. México: Porrúa.

Deutsche Gesetzestexte. (s. f.). Obtenido de https://www.gesetzesweb.de/HGB.html

FIESSER, J. (2015). Ética. Wikipedia. Recuperado de https://es.wikipedia.org/wiki/\%C3\%89tica\#cite_note-2

GENERALIDAD TRIBUTARIA. NATURALEZA JURIDICA Y ALCANCES DE ESE PRINCIPIO. 811/2008 (primera sala 2018 de noviembre 5).

IMCO (2017). Índice de Precepción de la Corrucpción2017 vía Transparencia Internacional. Recuperado de https://imco.org.mx/temas/indicepercepcion-la-corrupcion-2017-via-transparencia-internacional/

INEGI (2017). Estadisticas a propósito del día del... día de la administración pública. Recuperado de http://www.inegi.org.mx/saladeprensa/aproposito/2017/publica2017 _Nal.pdf 
MABARAK CERECEDO, D. (2004). Derecho financiero público. México: Mc.Graw Hill.

MABARAK CERECEDO, D. (2008). Derecho fiscal aplicado. Estudio específico de los impuestos. México: Mc Graw Hill.

MARGAIN MANAUTOU, E. (2009). La base imponible. México: Porrúa.

MORENO, C. (2014). Registro Federal de Contribuyentes. Descubre las ventajas de contar con él. Recuperado de https://www.condusef.gob.mx/Revista/PDF-s/2014/171/rfc.pdf

OCDE/CEPAL/CIAT. Estadísticas Tributarias en América Latina, OECD Publishing.

ORTEGA CARREÓN, C. A. (2012). Derecho Fiscal. México: Porrúa.

ORTEGA CARREÓN, C. A. (2014). Derecho Fiscal. México: Porrúa.

PLANEACIÓN DEMOCRÁTICA DEL DESARROLLO NACIONAL Y DEL SISTEMA NACIONAL DE DESARROLLO SOCIAL. Constitución Política de los Estados Unidos Mexicanos, 76/2009 (Tribunal pleno 01 de Julio de 2009).

RIQUELME, R. (2017). El Economista. Recuperado de https://www.eleconomista.com.mx/sectorfinanciero/En-que-paisesse-pagan-mas-impuestos-20170715-0006.html

SÁNCHEZ MIRANDA, A. (2013). Aplicación práctica del Código Fiscal. México: ISEF.

SUPREMA CORTE DE JUSTICIA DE LA NACIÓN (2009). Planeación Democrática del Desarrollo Nacional y Sistema Nacional de Desarrollo Social. México.

VARGAS ORTIZ, G. (2018). Aristegui Noticias. Recuperado de https://aristeguinoticias.com/2802/mexico/gasto-en-publicidadoficial-del-gobierno-de-epn-equivale-al-de-reconstruccion-en-cdmxarticulo-19/

Xihmai 134 
Eduardo Trejo Lino

La cultura tributaria en México como instrumento de identidad nacional

Revista Xihmai XIII (26), 115-136, julio-diciembre 2018

VENEGAS ÁLVAREZ, S. (2010). Derecho fiscal. México: Oxford.

YANOME YESAKI, M. (2009). Compendio de Derecho Fiscal. México:

Porrúa.

Xihmai 135 
Eduardo Trejo Lino

La cultura tributaria en México como instrumento de identidad nacional Revista Xihmai XIII (26), 115-136, julio-diciembre 2018

Xihmai 136 